\title{
SIMULTANEOUS OBSERVATIONS OF THE CONTINUUM EMISSION OF THE QUASAR 3C 273 FROM RADIO TO $\gamma$-RAY ENERGIES
}

G. G. LICHTI, T. BALONEK, T. J.-L. COURVOISIER, N. JOHNSON,

M. McCONNELL, C. von MONTIGNY, W. PACIESAS, E. I. ROBSON,

A. SADUN, C. SCHALINSKI, A. G. SMITH, R. STAUBERT, H. STEPPE ${ }^{+}$,

B. N. SWANENBURG, M. J. L. TURNER, M.-H. ULRICH, O. R. WILLIAMS

ABSTRACT. From June 15 to 28, 1991 the Compton Gamma-Ray Observatory (CGRO) observed the radio-loud quasar 3C 273. All four CGRO instruments detected radiation from this quasar in their relevant energy range (from $20 \mathrm{keV}$ to $5 \mathrm{GeV}$ ). Simultaneous and quasi-simultaneous observations (spanning the time period May 27 - July $25,1991)$ by instruments sensitive at other wavelengths have also been obtained. The data from all these observations spanning the frequency range from $\sim 10^{9} \mathrm{~Hz}$ to $\sim 10^{26}$ $\mathrm{Hz}$ were collected and analysed. The resulting energy-density spectrum is shown in the figure below. It shows two maxima, one in the UV, another one at low-energy $\gamma$-rays which have nearly the same strength (the corresponding luminosities per decade of frequency for $\mathrm{H}_{0}=60(\mathrm{~km} / \mathrm{s}) / M p c$ are $3.2 \cdot 10^{46} \mathrm{erg} / \mathrm{s}$ and $2.7 \cdot 10^{46} \mathrm{erg} / \mathrm{s}$, respectively). A break of the spectrum at low-energy $\gamma$-rays is evident. From a detailed analysis a break energy of $(2 \pm 1.5) \mathrm{MeV}$ could be derived corresponding to a frequency of $(4.8 \pm 3.6) \cdot 10^{20}$ $\mathrm{Hz}$. The observed spectral break between $\mathrm{X}$ - and $\gamma$-rays is $\sim 0.8$, much higher than the value of 0.5 predicted by some models. A more detailed paper on this topic is in preparation (Lichti et al.).

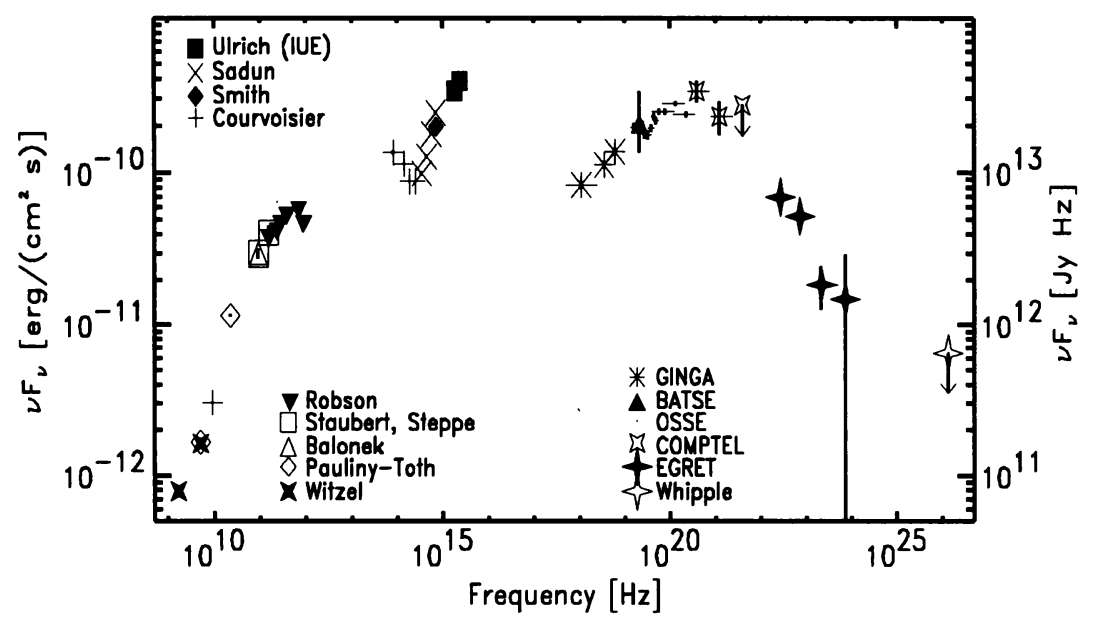

Energy-density spectrum of $3 \mathrm{C} 273$ from quasi-simultaneous observations.

\section{Acknowledgements}

We thank I. Pauliny-Toth for supplying his radio data on $3 \mathrm{C} 273$. We are grateful to $T$. Weekes for giving us the upper limit at ultra-high energies prior to publication.

+ Hans Steppe perished on June 30, 1993 during a hiking tour in the Alps. 